\title{
Body weight and comorbidity predict mortality in COPD patients treated with
} oxygen therapy

\author{
S. Marti*, X. Muñoz*, J. Rios ${ }^{\#}$, F. Morell* and J. Ferrer*
}

ABSTRACT: The aim of this study was to investigate the association between clinical variables and all-cause and respiratory mortality in patients with chronic obstructive pulmonary disease (COPD) undergoing long-term oxygen therapy (LTOT).

The authors retrospectively studied a historic cohort of 128 patients with COPD (126 males, mean age \pm SD $68.9 \pm 9.7 \mathrm{yrs}$, body mass index (BMI) $25.1 \pm 4.5 \mathrm{~kg} \cdot \mathrm{m}^{-2}$, and forced expiratory volume in one second $25.4 \pm 8.8 \%$ predicted), who were being treated with long-term oxygen therapy in a tertiary teaching hospital between 1992 and 1999. Comorbidity, assessed with the Charlson Index, was present in $38 \%$ of the patients. Vital status and cause of death were assessed through the population death registry.

A total of 78 patients (61\%) had died by the end of follow-up. Three-year survival was $55 \%$.

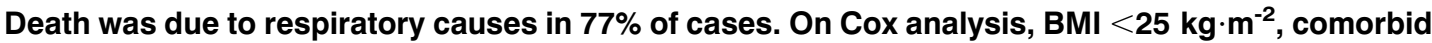
conditions, age $\geqslant \mathbf{7 0}$ yrs and cor pulmonale were associated with all-cause mortality. The BMI and comorbidity were the only significant predictive factors when the analysis was restricted to respiratory mortality.

In conclusion, body mass index $<25 \mathrm{~kg} \cdot \mathrm{m}^{-2}$ and comorbidity were predictors of all-cause and respiratory mortality in a cohort of chronic obstructive pulmonary disease patients treated with long-term oxygen therapy. These factors should be taken into account when considering the management and prognosis of these patients.

KEYWORDS: Chronic obstructive pulmonary disease, comorbidity, mortality, oxygen inhalation therapy, weight loss

hronic obstructive pulmonary disease (COPD) is a common condition affecting $4-9 \%$ of the adult population [1, 2]. In contrast to other diseases, COPD-related mortality has continued to increase in the general population [3].

COPD is a progressive disease that often leads to respiratory failure and death [2]. Long-term oxygen therapy (LTOT) is the single treatment that has proven to be effective in increasing survival in COPD patients with chronic respiratory failure $[4,5]$. Nevertheless, the life expectancy in COPD patients receiving LTOT is poor, with a 5 -yr survival rate of $\sim 40 \%[5,6]$. Although it has been the subject of several studies, there is still some controversy regarding the risk factors associated with death in these patients. Respiratory function parameters (e.g. forced expiratory volume in one second (FEV1)), arterial blood gases (e.g. arterial oxygen tension $\left(\mathrm{Pa}_{\mathrm{a}} \mathrm{O}_{2}\right)$ and carbon dioxide arterial tension $\left.\left(\mathrm{Pa}_{1}, \mathrm{CO}_{2}\right)\right)$, pulmonary hypertension, sex, age and body mass index (BMI), among others, are reported factors associated with mortality in these patients [6-13]. However, none of these variables have achieved a clear predictive value in all of the studies in which they were examined. This discrepancy may be partly related to the heterogeneity of the methods used. In some studies, the inclusion criteria are not clearly stated; hence, other factors, such as the presence of associated lung diseases, may have influenced mortality [9]. Moreover, variables such as comorbidity, which has been associated with mortality in patients with COPD [14-16], may not have been assessed in the subgroup with LTOT. Another aspect that may contribute to this discrepancy is the way in which the information on mortality was obtained. In some studies, no data are available regarding this point, and in others, the information source is the population death registry. In addition, most studies only consider overall mortality; respiratory mortality is included as an outcome measure in only one study [6].

\section{AFFILIATIONS}

* Servei de Pneumologia, Hospital General Vall d'Hebron, and * Laboratori de Bioestadística i

Epidemiologia, Universtitat Autònoma de Barcelona, Barcelona, Spain.

CORRESPONDENCE

J. Ferrer

Servei de Pneumologia Hospital General Vall d'Hebron Passeig Vall d'Hebron 119-129 08035 Barcelona Spain

Fax: 34932746083

E-mail: jjferrer@vhebron.net

Received:

June 302005

Accepted after revision:

December 122005

SUPPORT STATEMENT

Financed in part by a grant from Fundació Catalana de Pneumologia and by Red Respira-ISCIII-RTIC-03/ 11. 
The aim of the present study was to retrospectively analyse the variables associated with mortality in a historic cohort of COPD patients undergoing LTOT. The study design included careful selection of the patients in order to exclude those with associated pulmonary disease, and a comorbidity evaluation using a validated method [17]. All-cause mortality and respiratory mortality were both considered primary outcome variables.

\section{PATIENTS AND METHODS \\ Patients}

All patients with COPD initiating LTOT $>15 \mathrm{~h} \cdot \mathrm{day}^{-1}$ during 1992-1999 in the Oxygen Therapy Control Unit of a tertiary teaching hospital (Vall d'Hebron Hospital, Barcelona, Spain) with an urban catchment population of 450,000 inhabitants were considered for inclusion in the study. The patients were referred by their managing physicians. Patients were stable when LTOT was indicated and $\geqslant 3$ months had passed since an acute exacerbation of the disease. Patients who were still active smokers were strongly advised to give up the habit.

The indication for LTOT was based on the criteria of the Spanish Society of Respiratory Diseases [18]. Briefly, patients were selected for LTOT when room-air $\mathrm{Pa}_{1} \mathrm{O}_{2}$ was $<7.3 \mathrm{kPa}$ or $7.3-8.0 \mathrm{kPa}$ and there were associated signs of cor pulmonale, polycythaemia or arrhythmia. The diagnosis of COPD was established by clinical assessment and pulmonary function testing (FEV1 $<80 \%$ predicted and FEV1/forced vital capacity (FVC) ratio $<70 \%$ ). Patients with asthma or bronchiectasis were not included.

LTOT was withdrawn 3 months after initiation in patients whose blood gas results had improved $\left(\mathrm{Pa}_{\mathrm{a}} \mathrm{O}_{2}>8 \mathrm{kPa}\right)$ and in those who did not adhere to the treatment. Patients with any of the following factors were excluded from the study: 1) associated restrictive disorder (e.g. tuberculosis sequelae); 2) other clinically significant coexisting respiratory diseases (e.g. sleep apnoea/hypopnoea syndrome); 3) end-stage malignancies that might compromise short-term survival; or 4) inability to achieve $\mathrm{Pa}_{1} \mathrm{O}_{2}>8 \mathrm{kPa}$ with oxygen administration. Patient selection is shown in figure 1 .

The study protocol was approved by the hospital ethics committee.

\section{Baseline measurements and definitions}

Baseline studies included history-taking and physical examination, electrocardiogram (ECG), chest radiograph, and spirometry study (Datospir 200; Sibel, Barcelona, Spain). The reference spirometry values were those reported by RocA et al. [19]. Arterial blood gases were determined with a $\mathrm{pH}$ and blood gas analyser (IL-1306; Instrumentation Laboratories, Milan, Italy). Arterial blood gas testing was performed with the patient seated at rest and breathing room air, and again after $30 \mathrm{~min}$ of oxygen administration through nasal prongs, attempting to reach $\mathrm{Pa}_{\mathrm{a}} \mathrm{O}_{2}$ values $>8.6 \mathrm{kPa}$. Height and weight were measured and the BMI was calculated (weight in $\mathrm{kg}$ divided by height in $\mathrm{m}^{2}$ ).

Cor pulmonale was defined as the presence of two or more of the following criteria: 1) right ventricular hypertrophy or right atrial enlargement on the ECG; 2) enlarged pulmonary arteries on the chest radiograph; and 3) pedal oedema. Baseline

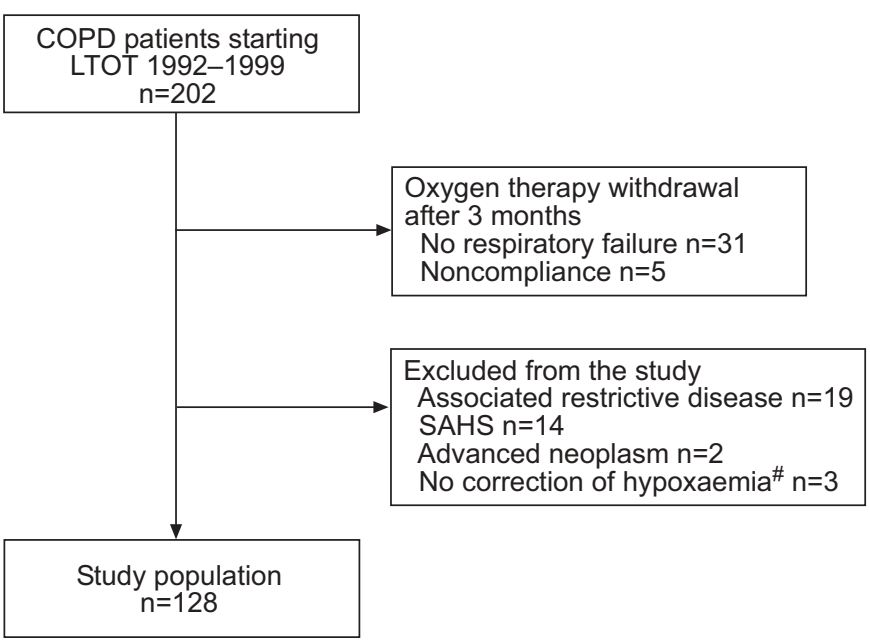

FIGURE 1. Chronic obstructive pulmonary disease (COPD) population included in the study. LTOT: long-term oxygen therapy; SAHS: sleep apnoea/ hypopnoea syndrome. * : Two patients with concomitant pulmonary shunt and one patient with increasing hypercapnia precluding increased oxygen flow.

comorbid conditions were recorded as a Charlson Index [17]. This system, developed to predict the impact of comorbidity on prognosis in longitudinal studies, assigns each disease a score of 1 to 6 , which is proportional to the disease-related risk of death. A score of 1 is allocated to myocardial infarction, congestive heart failure, peripheral vascular disease, cerebrovascular disease, dementia, connective tissue disease, ulcer disease, mild liver disease and diabetes. A score of 2 is assigned to diabetes with end-organ damage, hemiplegia, renal disease and malignancies, including leukaemia and lymphoma. A score of 3 is ascribed to moderate or severe liver disease, while AIDS and metastatic malignancies are attributed a score of 6. COPD was excluded from the list for the present study. The baseline characteristics were recorded systematically in a computer database.

\section{Oxygen treatment}

The prescription for oxygen treatment was $>15 \mathrm{~h} \cdot \mathrm{day}^{-1}$, at a flow rate determined in the laboratory, usually $1-3 \mathrm{~L} \cdot \mathrm{min}^{-1}$. The oxygen supply was provided by an oxygen concentrator in most patients and by liquid oxygen in a few cases. The patients and their families were instructed in the use of the oxygen delivery system. The oxygen equipment was provided by the supplier, which also carried out technical servicing in the patient's home. All costs were covered by the National Health System, which provides the population with total medical coverage.

\section{Follow-up}

Patients were managed clinically by their referring physicians, who were unaware of the ongoing study. All patients were seen at least once a year in the oxygen therapy control unit in order to assess LTOT compliance and adapt oxygen flow, if necessary.

Patients were included in the study at the time that LTOT was indicated, and follow-up ended in December 2000. Data on the patient's vital status was obtained from the Catalan Death Registry, which provided the basic causes of death compiled 
from the death certificates and coded according to the 10th revision of the International Classification of Diseases (ICD)-10 [20].

\section{Statistical analysis}

Assessment of baseline homogeneity between survivors and deceased patients was performed by means of the unpaired t-test for continuous variables, the Mann-Whitney test for ordinal variables and Fisher's exact test for qualitative variables. Results are expressed as mean \pm SD for quantitative variables, and as frequencies and percentages for qualitative and ordinal variables. The Kaplan-Meier method was used to estimate the survival function and the Cox proportional hazards model was used to perform the adjusted analysis [21]

The selection of independent variables for multivariate analysis was based on statistical significance obtained in the bivariate analysis $(\mathrm{p}<0.10)$ or on biological plausibility. A forward stepwise procedure was used and results are expressed as hazards ratio with $95 \%$ confidence intervals (CI). Data from cases receiving a treatment that could have modified the course of the disease were censored beyond that time point. Separate analyses were performed for all-cause mortality and respiratory mortality (ICD-10 codes J00-J99). BMI was stratified using standard categories $(<20,20-24.9,25-$ 29.9 and $\geqslant 30$ ) and age was set at $<70$ or $\geqslant 70$ yrs. Reference levels for categorical variables were selected according to the lowest risk (hazard ratio estimate) for mortality.

Statistical significance was set at a two-tailed p-value of $\leqslant 0.05$ for all tests.

\section{RESULTS}

\section{Clinical characteristics}

From a total of 202 COPD patients initiating LTOT during 1992-1999, 128 were included in the study (fig. 1). Characteristics of the total cohort at baseline, overall and according to vital status at the end of follow-up, are shown in table 1. Most patients were male (98\%), and $\sim 69$ yrs old. Weight distribution was as follows: $15(12 \%)$ were underweight (BMI <20), 50 (39\%) were normal (BMI 20.0-24.9), 47 $(36 \%)$ were overweight (BMI 25.0-29.9) and $16(13 \%)$ were obese (BMI $\geqslant 30)$. The majority of patients $(95 \%)$ were current or former smokers, and most had severe bronchial obstruction and mild hypercapnia $\left(\mathrm{Pa}_{\mathrm{a}} \mathrm{CO}_{2}>6 \mathrm{kPa}\right.$ in 81 cases, $63 \%$ ). Cardiovascular diseases and diabetes were the most frequent comorbid conditions (table 2). Follow-up was performed by pulmonologists in $93(73 \%)$ patients and by general practitioners in the remaining cases. Additional treatment administered for COPD is shown in table 3.

\section{Follow-up and mortality}

Patients were followed-up for a median of 3.2 yrs (interquartile range 1.1-6.9). In six survivors, follow-up ended before December 2000 because another treatment had been initiated: noninvasive mechanical ventilation in three patients, lung transplantation in two patients and surgery for pulmonary bullae in one patient. No patients were lost to follow-up.

By the end of follow-up, 78 patients $(61 \%)$ had died. In the bivariate analysis, patients who died were older, had a lower $\mathrm{BMI}$, and a higher frequency of cor pulmonale and comorbid conditions as compared to the survivors. The 1-, 3- and 5-yr survival rates were 0.79 (95\% CI 0.72-0.86), $0.55(0.46-0.64)$ and $0.34(0.24-0.44)$, respectively (fig. 2). The causes of death are shown in table 4 . Among the 78 deaths, 60 (77\%) were due to respiratory causes.

Multivariate Cox analysis included the following variables: age, sex, BMI, FEV1 (\% pred), FVC (\% pred), $\mathrm{Pa}_{2} \mathrm{O}_{2}, \mathrm{~Pa}_{2} \mathrm{CO}_{2}$, cor pulmonale, oral corticosteroid therapy, comorbid conditions and COPD-related hospitalisation in the previous year. The independent predictive factors for overall mortality in these patients are presented in table 5. Presence of cor pulmonale and age $\geqslant 70$ yrs were associated with increased mortality. Another significant factor was the presence of comorbid conditions. The risk of death increased at least three-fold for a Charlson index $\geqslant 2$, assuming the lower limit of the $95 \% \mathrm{CI}$ as the minimum risk associated with the present data. The relationship between BMI categories and hazard ratio for mortality is shown in figure 3. When BMI 25-29.9 was taken as the reference category, values $<25$ were associated with increased mortality (table 5). Using a BMI of 20-24.9 as a reference, the relative hazard ratios were 1.73 (95\% CI $0.81-$ 3.67; $\mathrm{p}=0.15), 0.33(0.19-0.58 ; \mathrm{p}<0.001)$ and $0.57(0.26-1.24$; $\mathrm{p}=0.15)$ for $\mathrm{BMI}<20,25-29.9$ and $\geqslant 30$, respectively. In the analysis of death exclusively by respiratory causes, only the BMI and comorbidity were significant predictive factors (table 5). Kaplan-Meier survival curves for all-cause mortality according to BMI and comorbidity categories are shown in figure 4 .

\section{DISCUSSION}

In this study, a BMI $<25 \mathrm{~kg} \cdot \mathrm{m}^{-2}$ and the presence of comorbid conditions as assessed by the Charlson Index were predictive factors for all-cause and respiratory mortality in a cohort of COPD patients treated with LTOT.

A low BMI $(<20)$ has been found in $20-30 \%$ of patients with advanced COPD $[7,22]$ and has proved to be a predictive factor for mortality in these patients regardless of pulmonary function status [22-25]. The role of body weight as an indicator of mortality in the COPD population treated with LTOT was assessed in two prior studies, which showed discordant results. Whereas one reported an inverse relationship between BMI and mortality [7], the other showed no relationship between these factors in the adjusted analysis [9]. The present results showed that the BMI category associated with the lowest risk of mortality was 25-29.9. Therefore, 25-29.9 was chosen as the reference category for analysing this factor, rather than 20-24.9, which is considered to represent the normal weight in the general population. On that basis, a higher risk of death was found not only in patients with BMI $<20$, but also in those with BMI 20-24.9. As is clearly seen figure 3, the risk of death increases both above and below 2529.9 , regardless of the BMI taken as reference. These findings concur with results from other studies, which show a gradual increase in the risk of death as weight decreases in patients with COPD [7, 22-25]. However, the fact that patients with a normal BMI were at a higher risk cannot be clearly explained. ScHOLs et al. [26] described depletion of the fat-free mass in $9 \%$ of patients with COPD and a normal BMI. In fact, a measure of this fat-free mass, the mid-thigh muscle cross-sectional area assessed by computed tomography, has been shown to be a 


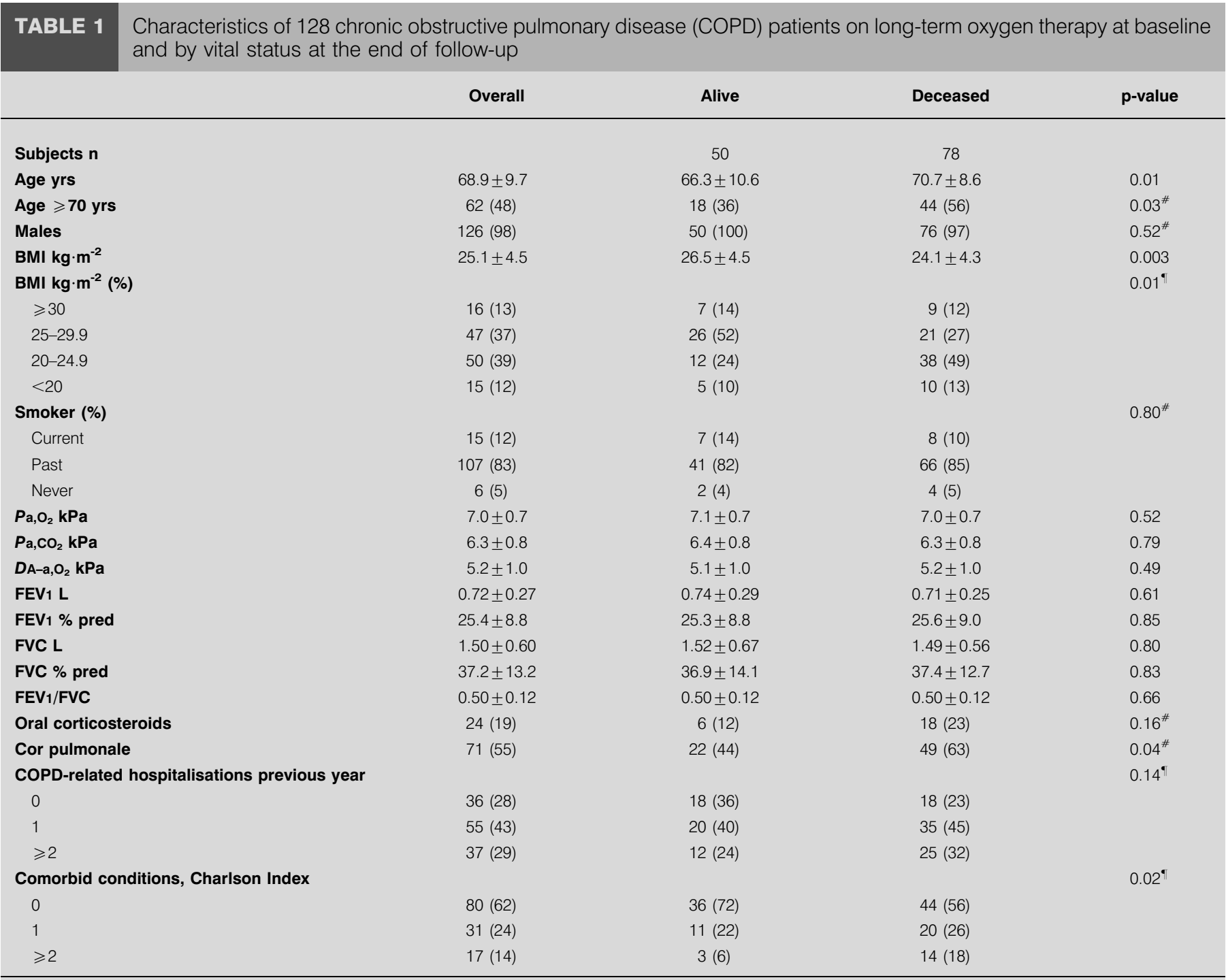

Data are presented as mean \pm SD or $n(\%)$, unless otherwise stated. Statistical tests used were unpaired t-test, except where indicated by ${ }^{\#}$ and " where Fisher's exact test and Mann-Whitney test were used, respectively. BMI: body mass index; $\mathrm{Pa}_{2} \mathrm{O}_{2}$ : arterial oxygen tension; $\mathrm{Pa}_{1} \mathrm{CO}_{2}$ : carbon dioxide arterial tension; $\mathrm{DA}-\mathrm{a}, \mathrm{O}_{2}$ : alveolar-arterial oxygen difference; FEV1: forced expiratory volume in one second; \% pred: \% predicted; FVC: forced vital capacity.

better predictor of mortality than BMI in patients with COPD [27]. Furthermore, fat-free mass has recently been identified as an independent risk factor for mortality in COPD patients, regardless of the fat mass [28]. Hence, protein depletion may be a negative feature in the prognosis of these patients, even though their weight is normal. This evidence may help to explain why 25-29.9 was the BMI category with the lowest associated risk of death. Thus, as has been shown in previous studies [7, 22-25], being overweight may have a positive effect on the prognosis in the COPD population.

The present results indicate that comorbidity as measured by the Charlson Index was associated with both all-cause and respiratory mortality. Prior studies have reported the Charlson Index to be a predictor of mortality in both medical [17] and surgical [29] patients. The Index has also been used in patients with COPD, but the results are not consistent; some authors have found an association with mortality [14-16], whereas others have not [30-33]. This discrepancy may be due to methodological differences among the studies, particularly with regard to heterogeneity among the populations included, and the phase, exacerbated or stable, in which the disease was studied. The present study is the first to measure comorbidity as a risk factor for mortality in COPD patients receiving LTOT. In keeping with previous studies, COPD was excluded as a variable when calculating the Index [15]. The association between comorbidity and all-cause mortality suggests that comorbidity may have exerted some influence on the nonrespiratory causes of death. Nevertheless, the majority of the patients died of respiratory causes (77\%) and comorbidity also proved to be a factor associated with respiratory death. As has been suggested [30], comorbidity may have an influence on the severity of the acute respiratory complications that determine death in these patients. Moreover, comorbid conditions might 


\begin{tabular}{ll} 
TABLE 2 & $\begin{array}{l}\text { Chronic conditions at baseline according to the } \\
\text { Charlson Index in } 128 \text { chronic obstructive } \\
\text { pulmonary disease patients starting long-term } \\
\text { Oxygen therapy }\end{array}$ \\
Congestive heart failure & $17(13)$ \\
Diabetes & $11(9)$ \\
Myocardial infarction & $9(7)$ \\
Mild liver disease & $9(7)$ \\
Peripheral vascular disease & $4(3)$ \\
Peptic ulcer disease & $3(2)$ \\
Malignant neoplasm (not metastatic) & $3(2)$ \\
Renal disease & $2(2)$ \\
Dementia & $2(2)$ \\
Leukaemia & $1(1)$ \\
Cerebrovascular disease & $1(1)$ \\
Diabetes with chronic complications & $1(1)$ \\
\hline & \\
Data presented as $n$ (\%). &
\end{tabular}

\begin{tabular}{ll} 
TABLE 3 & $\begin{array}{l}\text { Pharmacological treatment in } 128 \text { chronic } \\
\text { obstructive pulmonary disease patients starting } \\
\text { long-term domiciliary oxygen therapy }\end{array}$ \\
\hline Inhaled $\boldsymbol{\beta}_{\mathbf{2}}$-agonists & $114(89)$ \\
Inhaled ipratropium & $103(80)$ \\
Inhaled corticosteroids & $103(80)$ \\
Diuretics & $59(46)$ \\
Xanthines & $58(45)$ \\
Oral corticosteroids & $24(19)$ \\
\hline
\end{tabular}

Data presented as $n(\%)$.

trigger events that would increase the frequency of exacerbations, such as pulmonary thromboembolism or vertebral fractures.

Among the variables that reflect the severity of COPD, only cor pulmonale was associated with all-cause mortality in the present study. However, the authors recognise that they used

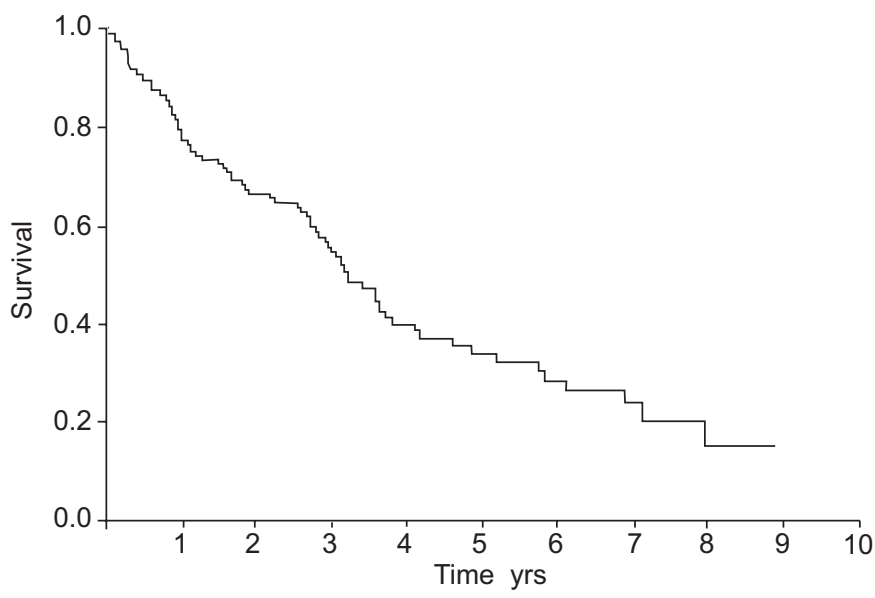

FIGURE 2. Kaplan-Meier survival curve for all-cause mortality in 128 chronic obstructive pulmonary disease patients starting long-term oxygen therapy.

\section{TABLE 4 Causes of death}

\begin{tabular}{lcc}
\multicolumn{1}{c}{ Causes } & ICD-10 codes & Subjects \\
\hline COPD-related & J40-J47 & $51(65)$ \\
Other respiratory causes & J00-J39; J48-J99 & $9(12)$ \\
Cardiovascular diseases & $100-199$ & $7(9)$ \\
Lung cancer & C33-C34 & $3(4)$ \\
Other cancers & C00-C32; C35-D09 & $5(6)$ \\
All other causes & & $3(4)$ \\
Total & & $78(100)$ \\
\hline
\end{tabular}

Data presented $n(\%)$, unless otherwise stated. ICD-10: International Classification of Diseases-10; COPD: chronic obstructive pulmonary disease.

clinical criteria to define cor pulmonale, a fact that could limit the reliability of this finding. Cor pulmonale is a known factor of poor prognosis in COPD patients [34, 35], but the impact of this condition on those receiving LTOT is uncertain. In most studies, cor pulmonale was not included as a variable to be analysed. Another factor that is highly related to cor pulmonale, pulmonary hypertension as measured by cardiac catheterisation, was associated with mortality in another cohort of COPD patients undergoing LTOT [11]. Pulmonary function and blood gas variables showed no association with mortality in the present patients. In previous studies, the results relative to this point are not concordant. FEV1, $\mathrm{Pa}_{\mathrm{a}} \mathrm{O}_{2}$ and $\mathrm{Pa}_{\mathrm{a}} \mathrm{CO}_{2}$ have shown associations in some studies $[7,9,12]$ but not others $[10,11]$. Once again, these differences may partly be due to dissimilar characteristics of the patients studied. In addition, with regard to hypoxaemia, it is likely that initiation

\section{TABLE 5 Prognostic factors according to Cox models for all-cause and respiratory mortality}

\begin{tabular}{|c|c|c|c|c|}
\hline & \multicolumn{2}{|c|}{ All-cause mortality } & \multicolumn{2}{|c|}{ Respiratory mortality } \\
\hline & HR (95\% Cl) & $\mathrm{p}$-value & HR $(95 \% \mathrm{Cl})$ & p-value \\
\hline \multicolumn{5}{|l|}{ Age yrs } \\
\hline$<70$ & 1 & & 1 & \\
\hline$\geqslant 70$ & $1.85(1.12-3.07)$ & 0.02 & $1.43(0.81-2.53)$ & 0.21 \\
\hline \multicolumn{5}{|c|}{ BMI $\mathbf{k g} \cdot \mathbf{m}^{-2}$} \\
\hline$\geqslant 30$ & $1.70(0.74-3.86)$ & 0.21 & $1.48(0.59-3.71)$ & 0.41 \\
\hline $25-29.9$ & 1 & & 1 & \\
\hline $20-24.9$ & $3.00(1.72-5.24)$ & $<0.001$ & $2.07(1.42-5.07)$ & 0.002 \\
\hline$<20$ & $5.18(2.69-11.84)$ & $<0.001$ & $4.95(2.04-12.01)$ & $<0.001$ \\
\hline \multicolumn{5}{|c|}{ Cor pulmonale } \\
\hline No & 1 & & 1 & \\
\hline Yes & $1.73(1.07-2.78)$ & 0.02 & $1.56(0.91-2.67)$ & 0.10 \\
\hline $\begin{array}{l}\text { Comorbidi } \\
\text { Index) }\end{array}$ & \multicolumn{3}{|c|}{ Comorbidity (Charlson } & \\
\hline 0 & 1 & & 1 & \\
\hline 1 & $1.69(0.96-2.97)$ & 0.07 & $1.85(0.98-3.49)$ & 0.07 \\
\hline$\geqslant 2$ & $7.21(3.60-14.46)$ & $<0.001$ & $6.64(3.04-14.48)$ & $<0.001$ \\
\hline
\end{tabular}

HR: hazard ratio; Cl: confidence interval; BMI: body mass index. ${ }^{\#}$ : according to the International Classification of Diseases-10, codes J00-J99. 


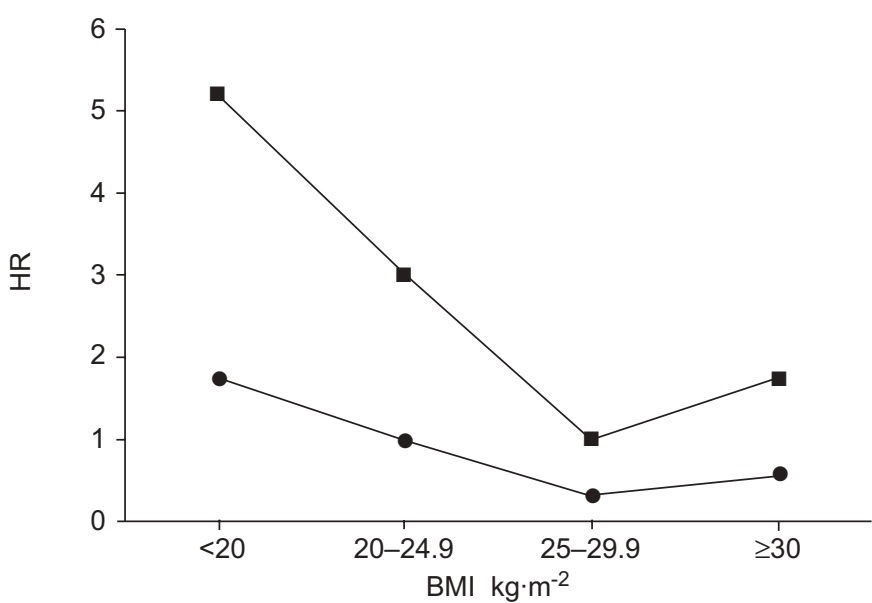

FIGURE 3. All-cause mortality according to body mass index (BMI) in 128 chronic obstructive pulmonary disease patients starting long-term oxygen therapy. BMI 20-24.9 ( $)$ and 25-29.9 (অ) $\mathrm{kg} \cdot \mathrm{m}^{-2}$ were used for reference. BMI: body mass index; HR: hazard ratio
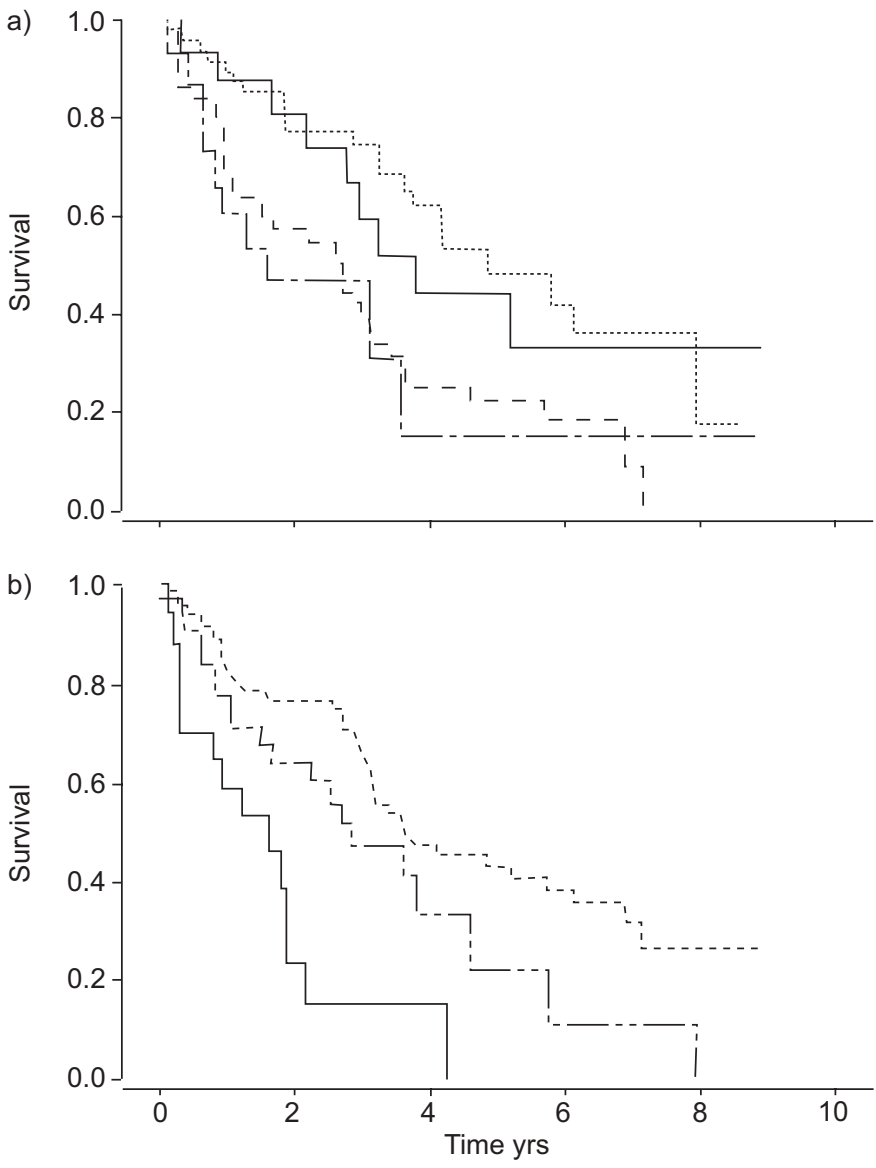

FIGURE 4. Kaplan-Meier survival curves for all-cause mortality according to a) body mass index (BMI) and b) comorbidity (Charlson Index), in 128 chronic obstructive pulmonary disease patients starting long-term oxygen therapy. a) —

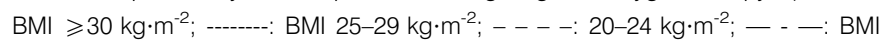
$<20 \mathrm{~kg} \cdot \mathrm{m}^{-2} \cdot$ b) - - - - : Charlson Index 0; — -- _: Charlson Index 1; —_ Charlson Index $\geqslant 2$. of LTOT as corrective therapy would cancel out the effect of this unfavourable prognostic factor.

Some potential limitations of the present study deserve comment. First, the lengthy period of inclusion and followup, which is necessary in a cohort study, can imply a series of changes in the diagnostic and therapeutic procedures used that might affect the results. However, during the study period, no substantial changes were incorporated into the management of these patients. In fact, Cox analysis in patients recruited in the early years of the study (1992-1995) versus those recruited later (1996-1999), showed no significant differences with regard to the factors predicting mortality (results not shown). Secondly, the cohort studied contains very few females. This can probably be attributed to the relatively late initiation of the habit of smoking among females in Spain [1]. As a result and taking into account the fact that differences in mortality have been related to sex in patients with LTOT $[5,6]$, the present results cannot be generalised to the female COPD population. Another potential limitation centres on the validity of death certificates as the basis for determining the cause of death Some authors have suggested that there is a tendency to underestimate COPD when multiple causes of death are not taken into account $[36,37]$. Despite this, in the present COPD was cited as the cause of death in $65 \%$ of the certificates and other respiratory diseases were cited in $12 \%$. In keeping with the study by ZIELINSKI et al. [38], who examined causes of death in 215 patients on LTOT in seven European countries, the majority of patients with advanced COPD undergoing this treatment died due to respiratory causes. Therefore, the present authors do not believe that underestimation of COPD as the cause of death has substantially affected the study's results.

In conclusion, the present findings suggest that among chronic obstructive pulmonary disease patients receiving long-term oxygen therapy, non-respiratory variables, such as body mass index $<25 \mathrm{~kg} \cdot \mathrm{m}^{-2}$ and associated comorbid conditions, are highly relevant factors in both all-cause and respiratory mortality. This suggests that a multidisciplinary approach, which includes nutritional support and appropriate management of the comorbid processes, may be preferable in these patients.

\section{ACKNOWLEDGEMENTS}

The authors would like to thank: T. Codinachs for nursing assistance: the Registre de Mortalitat de Catalunya (Servei d'Informació i Estudis, Direcció General de Recursos Sanitaris, Departament de Sanitat i Seguretat Social, Barcelona, Spain) for providing mortality data; the Laboratori de Bioestadística $i$ Epidemiologia (Universitat Autonoma de Barcelona, Barcelona, Spain) for advice on statistical analysis; and C. Cavallo for English translation.

\section{REFERENCES}

1 Pena VS, Miravitlles M, Gabriel R, et al. Geographic variations in prevalence and underdiagnosis of COPD: results of the IBERPOC multicentre epidemiological study. Chest 2000; 118: 981-989.

2 Loddenkemper RGibson GJSibille Y, eds. European Lung White Book: The First Comprehensive Survey on 
Respiratory Health in Europe. European Respiratory Society Journals, Sheffield, UK, 2003.

3 Murray CJ, Lopez AD. Mortality by cause for eight regions of the world: Global Burden of Disease Study. Lancet 1997; 349: 1269-1276.

4 Nocturnal Oxygen Therapy Trial Group. Continuous or nocturnal oxygen therapy in hypoxemic chronic obstructive lung disease: a clinical trial. Ann Intern Med 1980; 93: 391-398.

5 Long term domiciliary oxygen therapy in chronic hypoxic cor pulmonale complicating chronic bronchitis and emphysema. Report of the Medical Research Council Working Party. Lancet 1981; 1: 681-686.

6 Miyamoto K, Aida A, Nishimura M, Aiba M, Kira S, Kawakami Y. Gender effect on prognosis of patients receiving long-term home oxygen therapy. The Respiratory Failure Research Group in Japan. Am J Respir Crit Care Med 1995; 152: 972-976.

7 Chailleux E, Laaban JP, Veale D. Prognostic value of nutritional depletion in patients with COPD treated by long-term oxygen therapy: data from the ANTADIR observatory. Chest 2003; 123: 1460-1466.

8 Cooper CB, Waterhouse J, Howard P. Twelve year clinical study of patients with hypoxic cor pulmonale given long term domiciliary oxygen therapy. Thorax 1987; 42: 105-110.

9 Dubois P, Jamart J, Machiels J, Smeets F, Lulling J. Prognosis of severely hypoxemic patients receiving longterm oxygen therapy. Chest 1994; 105: 469-474.

10 Foucher P, Baudouin N, Merati M, et al. Relative survival analysis of 252 patients with COPD receiving long-term oxygen therapy. Chest 1998; 113: 1580-1587.

11 Oswald-Mammosser M, Weitzenblum E, Quoix E, et al. Prognostic factors in COPD patients receiving long-term oxygen therapy. Importance of pulmonary artery pressure. Chest 1995; 107: 1193-1198.

12 Skwarski K, MacNee W, Wraith PK, Sliwinski P, Zielinski J. Predictors of survival in patients with chronic obstructive pulmonary disease treated with long-term oxygen therapy. Chest 1991; 100: 1522-1527.

13 Strom K, Boe J. Quality assessment and predictors of survival in long-term domiciliary oxygen therapy. The Swedish Society of Chest Medicine. Eur Respir J 1991; 4: 50-58.

14 Almagro $\mathrm{P}$, Calbo E, Ochoa dE, et al. Mortality after hospitalization for COPD. Chest 2002; 121: 1441-1448.

15 Soriano JB, Vestbo J, Pride NB, Kiri V, Maden C, Maier WC. Survival in COPD patients after regular use of fluticasone propionate and salmeterol in general practice. Eur Respir J 2002; 20: 819-825.

16 Casanova C, Cote $C$, de Torres JP, et al. The inspiratory to total lung capacity ratio predicts mortality in patients with COPD. Am J Respir Crit Care Med 2005; 171: 591-597.

17 Charlson ME, Pompei P, Ales KL, MacKenzie CR. A new method of classifying prognostic comorbidity in longitudinal studies: development and validation. J Chronic Dis 1987; 40: 373-383.

18 Sanchez AL, Cornudella R, Estopa MR, Molinos ML, Servera PE. Guidelines for indications and use of domiciliary continuous oxygen therapy. SEPAR guidelines. Arch Bronconeumol 1998; 34: 87-94.
19 Roca J, Sanchis J, Agusti-Vidal A, et al. Spirometric reference values from a Mediterranean population. Bull Eur Physiopathol Respir 1986; 22: 217-224.

20 World Health Organization. International Statistical Classification of Disease and Related Health Problems, 10th revision. Geneva, Switzerland, World Health Organization, 1992.

21 Breslow NE, Day NE. Statistical methods in cancer research. Volume II. The design and analysis of cohort studies. IARC Sci Publ 1987; 82: 1-406.

22 Gray-Donald K, Gibbons L, Shapiro SH, Macklem PT, Martin JG. Nutritional status and mortality in chronic obstructive pulmonary disease. Am J Respir Crit Care Med 1996; 153: 961-966.

23 Landbo C, Prescott E, Lange P, Vestbo J, Almdal TP. Prognostic value of nutritional status in chronic obstructive pulmonary disease. Am J Respir Crit Care Med 1999; 160: 1856-1861.

24 Schols AM, Slangen J, Volovics L, Wouters EF. Weight loss is a reversible factor in the prognosis of chronic obstructive pulmonary disease. Am J Respir Crit Care Med 1998; 157: 1791-1797.

25 Wilson DO, Rogers RM, Wright EC, Anthonisen NR. Body weight in chronic obstructive pulmonary disease. The National Institutes of Health Intermittent Positive-Pressure Breathing Trial. Am Rev Respir Dis 1989; 139: 1435-1438.

26 Schols AMWJ, Soeters PB, Dingemans AMC, Mostert R, Frantzen PJ, Wouters EFM. Prevalence and characteristics of nutritional depletion in patients with stable COPD eligible for pulmonary rehabilitation. Am Rev Respir Dis 1993; 147: 1151-1156.

27 Marquis K, Debigare R, Lacasse Y, et al. Midthigh muscle cross-sectional area is a better predictor of mortality than bode mass index in patients with chronic obstructive pulmonary disease. Am J Respir Crit Care Med 2002; 166: 809-813.

28 Schols AMWJ, Broekhuizen R, Weling-Scheepers CA, Wouters EF. Body composition and mortality in chronic obstructive pulmonary disease. Am J Clin Nutr 2005; 82: 53-59.

29 Deyo RA, Cherkin DC, Ciol MA. Adapting a clinical comorbidity index for use with ICD-9-CM administrative databases. J Clin Epidemiol 1992; 45: 613-619.

30 Antonelli IR, Fuso L, De Rosa M, et al. Co-morbidity contributes to predict mortality of patients with chronic obstructive pulmonary disease. Eur Respir J 1997; 10: 2794-2800.

31 Groenewegen KH, Schols AM, Wouters EF. Mortality and mortality-related factors after hospitalization for acute exacerbation of COPD. Chest 2003; 124: 459-467.

32 Celli BR, Cote CG, Marin JM, et al. The body-mass index airflow obstruction, dyspnea, and exercise capacity index in chronic obstructive pulmonary disease. $N$ Eng J Med 2004; 350: 1005-1012.

33 Pinto-Plata VM, Cote C, Cabral H, Taylor J, Celli BR. The 6min walk distance: change over time and value as a predictor of survival in severe COPD. Eur Respir J 2004; 23: 28-33.

34 Incalzi RA, Fuso L, De Rosa M, et al. Electrocardiographic signs of chronic cor pulmonale: A negative prognostic finding in chronic obstructive pulmonary disease. Circulation 1999; 99: 1600-1605. 
35 Traver GA, Cline MG, Burrows B. Predictors of mortality in chronic obstructive pulmonary disease. A 15-year follow-up study. Am Rev Respir Dis 1979; 119: 895-902.

36 Hansell AL, Walk JA, Soriano JB. What do chronic obstructive pulmonary disease patients die from? A multiple cause coding analysis. Eur Respir J 2003; 22: 809-814.
37 Mannino DM, Brown C, Giovino GA. Obstructive lung disease deaths in the United States from 1979 through 1993. An analysis using multiple-cause mortality data. Am J Respir Crit Care Med 1997; 156: 814-818.

38 Zielinski J, MacNee W, Wedzicha J, et al. Causes of death in patients with COPD and chronic respiratory failure. Monaldi Arch Chest Dis 1997; 52: 43-47. 